\title{
Postoperative urinary retention in patients undergoing elective spinal surgery
}

\author{
David Altschul, MD, ${ }^{1}$ Andrew Kobets, MD, Jonathan Nakhla, MD, ${ }^{1}$ Ajit Jada, MD, ${ }^{1}$ \\ Rani Nasser, MD, ${ }^{1}$ Merritt D. Kinon, MD, ${ }^{1}$ Reza Yassari, MD, ${ }^{1}$ and John Houten, MD² \\ 'Department of Neurosurgery, Montefiore Medical Center and Albert Einstein College of Medicine of Yeshiva University, Bronx, \\ New York; and ${ }^{2}$ Marcus Neuroscience Institute, Boca Raton, Florida
}

\begin{abstract}
OBJECTIVE Postoperative urinary retention (POUR) is a common problem leading to morbidity and an increased hospital stay. There are limited data regarding its baseline incidence in patients undergoing spinal surgery and the risk factors with which it may be associated. The purpose of this study was to evaluate the incidence of POUR in elective spine surgery patients and determine the factors associated with its occurrence.

METHODS The authors retrospectively reviewed the records of patients who had undergone elective spine surgery and had been prospectively monitored for POUR during an 18-month period. Collected data included operative positioning, surgery duration, volume of intraoperative fluid, length of hospital stay, and patient characteristics such as age, sex, and medical comorbidities. Dialysis patients or those with complete urinary retention preoperatively were excluded from analysis.

RESULTS Of the 397 patients meeting the study inclusion criteria, 35 (8.8\%) developed POUR. An increased incidence of POUR was noted in those who underwent posterior lumbar surgery, those with benign prostatic hypertrophy (BPH), those with chronic constipation or prior urinary retention, and those using a patient-controlled analgesia pump postoperatively. An increased incidence of POUR was seen with a longer operative time but not with intraoperative intravenous fluid administration. A significant relationship between the female sex and POUR was noted after controlling for BPH, yet there was no association between POUR and diabetes or intraoperative instrumentation. Postoperative retention significantly prolonged the hospital stay. Three patients developed epidural hematomas necessitating operative reexploration, and while they experienced POUR, they also developed the full constellation of cauda equina syndrome.
\end{abstract}

CONCLUSIONS Awareness of the risk factors for POUR may be useful in perioperative Foley catheter management and in identifying patients who need particular vigilance when they are due to void postprocedure. A greater understanding of POUR may also prevent longer hospital stays in select at-risk patients. Postoperative retention is rarely caused by a postoperative cauda equina syndrome due to epidural hematoma, which is also associated with saddle anesthesia, leg pain, and weakness, yet the delineation of isolated POUR from this urgent complication is necessary for optimal patient care.

https://thejns.org/doi/abs/10.3171/2016.8.SPINE151371

KEY WORDS epidural hematoma; urinary retention; postoperative complications; risk factors; spinal surgery; laminectomy; cauda equina; POUR

$\mathrm{P}$ OSTOPERATIVE urinary retention (POUR) is a common problem in patients receiving general anesthesia and may lengthen the in-hospital stay and cause pain and morbidity. ${ }^{2,14}$ The adult bladder has a capacity of 400-600 ml. ${ }^{2}$ At $300 \mathrm{ml}$, parasympathetic-mediated detrusor contraction begins and a sense of "fullness" is experi- enced. Failure of the micturition circuit and/or its frontal and pontine regulatory centers may result in retention, or an inability to void in the presence of a full bladder. Extended periods of retention can result in detrusor overdistention and atony, urinary tract infection (UTI), renal injury, and discomfort.

ABBREVIATIONS BPH = benign prostatic hypertrophy; IVF = intravenous fluid; PCA = patient-controlled analgesia; POUR = postoperative urinary retention; UTI = urinary tract infection.

SUBMITTED December 1, 2015. ACCEPTED August 3, 2016.

INCLUDE WHEN CITING Published online October 21, 2016; DOI: 10.3171/2016.8.SPINE151371. 
Prior studies have focused on urinary retention following general surgery and obstetrical, gynecological, and orthopedic procedures, but there has been limited investigation in connection with elective spinal surgery. 1,3-6,8-11,13-17,19-24,26,30-32 There are differences in the patients undergoing spinal and nonspinal surgery including the type of positioning on the operating room table, pre- and postoperative narcotic usage, and manipulation of elements of the nervous system that contribute to bladder function. Thus it is possible that differences exist in the incidence of POUR in patients undergoing spinal surgery and that identifying a subpopulation at higher risk for urinary retention may help to avoid associated complications and thereby shorten the hospital stay. In addition, as urinary retention is a feature of cauda equina syndrome caused by postoperative epidural hematoma or abscess, an improved understanding of POUR may aid in identifying patients who require further workup and decompressive intervention..$^{25}$

\section{Methods}

All patients admitted to our tertiary care academic medical center over an 18-month period for elective spine surgery performed by 5 different academic neurosurgeons were monitored for urinary retention. The cases included cervical, thoracic, and lumbar surgeries via both anterior and posterior approaches. Patients with cervical and thoracic myelopathy and lumbar radiculopathy were deemed surgical candidates. Those with axial pain were referred for conservative therapies including steroid injections and physical therapy, among others, prior to consideration for surgical treatment.

Collected data included demographic information, presence of diabetes mellitus or benign prostatic hypertrophy $(\mathrm{BPH})$, history of retention (either as recorded in their charts or due to chronic catheterization), procedure positioning, surgical duration, anatomical location of surgery, use of instrumentation, Foley catheter placement, intraoperative intravenous fluids (IVFs) volume, use of postoperative patient-controlled analgesia (PCA), and hospital length of stay. These data were retrospectively collected using charted nursing, anesthesiology, and operative reports. Operative duration was measured from the start of anesthesia induction to patient extubation. Foley catheters were placed intraoperatively for each case expected to last more than 2 hours and were removed once the patient was ambulatory or able to transfer to a commode. All patients had pre- and postoperative urinalysis studies, and those with fevers or retention postoperatively had urine cultures.

Postoperative urinary retention was defined as failure to void more than 8 hours after surgery for patients without intraoperative Foley placement, failure to void more than 8 hours after Foley catheter removal for those with intraoperative placement, or the report of a distended or painful bladder (patients reported suprapubic pain or discomfort either at rest or with palpation by the nursing staff). Patients were routinely monitored with ultrasound when any of these 3 criteria were met as frequently as at hourly intervals, and all patients with more than 350-400 $\mathrm{ml}$ of fluid seen on ultrasound were catheterized intermit- tently at first and then had Foley catheters replaced if they required more than 2 intermittent catheterizations. Exclusion criteria included end-stage renal disease on hemodialysis, primary presentation with acute urinary retention, or urinary retention developed as part of a cauda equina syndrome in relation to a complication such as epidural abscess or epidural hematoma.

Stata statistical software (StataCorp.) was used to compare the POUR and non-POUR groups. Study design and progress were approved by the institutional review board of the Albert Einstein College of Medicine and Montefiore Medical Center. A p $<0.05$ was considered statistically significant.

\section{Results}

Of 402 patients who underwent elective spine surgery, 397 met our inclusion criteria as 3 patients were excluded for postoperative cauda equina syndrome due to epidural hematoma and 2 for end-stage renal disease on hemodialysis. A total of 35 patients $(8.8 \%$ ) developed POUR (Table 1). The median age for both groups was 60 years old, and the mean was 57 and 64 years for the non-retention and retention groups, respectively $(\mathrm{p}=0.002)$. Patient sex did not outright affect the incidence of retention $(p=0.21)$; however, after controlling for BPH, there was a significant association between the female sex and the development of POUR ( $p=0.012, \mathrm{OR}=2.4)$. Surgery was performed in cervical, thoracic, and lumbar locations in $41 \%, 2.5 \%$, and $56 \%$ of cases, respectively, in the non-retention group and $20 \%, 3 \%$, and $77 \%$ of cases, respectively, in the retention group. Retention was significantly associated with surgeries performed on the lumbar spine $(\mathrm{p}=0.019, \mathrm{OR}=2.7)$ compared with cervical and thoracic cases. In the retention group, $97 \%$ of cases were treated via a posterior approach, whereas in the non-retention group, $66 \%$ of cases were posterior $(p<0.001)$. The use of spinal instrumentation was not a significant factor for the prediction of retention $(p=1.0)$. In contrast, retention was associated with a significant increase in the hospital length of stay (6.3 vs 4 mean days, $\mathrm{p}<0.001)$, and $4(11 \%)$ of the 35 POUR patients were discharged with a Foley catheter and follow-up with a urologist.

A longer operative time correlated with a higher incidence of POUR; mean operative times for the non-retention and retention groups were 167 and 213 minutes, respectively $(p=0.013)$. Mean IVF administration in the retention and non-retention groups was $2429 \mathrm{ml}$ and 1867 $\mathrm{ml}$, respectively $(\mathrm{p}=0.084)$. Seventeen percent of patients who developed POUR had a history of retention, as compared with only a $1 \%$ in the non-retention group $(\mathrm{p}<0.001)$. A history of BPH was also noted in $17 \%$ of the retention cases, as compared with only $3 \%$ in the non-retention group $(\mathrm{p}=0.002, \mathrm{OR}=13.5$; Table 2). Diabetes mellitus was a comorbidity in $37 \%$ and $24 \%$ of cases in the retention and non-retention groups, respectively $(\mathrm{p}=0.103)$, and was not significantly associated with POUR. Twenty-six percent of retention patients presented with constipation versus $5 \%$ in the non-retention group $(\mathrm{p}<0.001, \mathrm{OR}=4.4)$. Of the patients who experienced urinary retention, $14 \%$ developed postoperative UTIs as compared with $5 \%$ in the 
TABLE 1. Factors associated with POUR in 397 elective spine surgery cases

\begin{tabular}{|c|c|c|c|}
\hline Parameter & $\begin{array}{l}\text { Urinary } \\
\text { Retention }\end{array}$ & $\begin{array}{l}\text { No Urinary } \\
\text { Retention }\end{array}$ & p Value \\
\hline No. of patients (\%) & $35(8.8)$ & $362(91.2)$ & \\
\hline \multicolumn{3}{|l|}{ Sex } & \multirow{3}{*}{0.21} \\
\hline M (no. [\%]) & $12(34.3)$ & $168(46.4)$ & \\
\hline $\mathrm{F}($ no. $[\%])$ & $23(65.7)$ & $194(53.6)$ & \\
\hline \multicolumn{3}{|l|}{$\operatorname{Sex}\left(\right.$ no $\left.B P H^{\star}\right)$} & \multirow{3}{*}{0.012} \\
\hline M (no. [\%]) & $6(20.7)$ & $157(44.7)$ & \\
\hline $\mathrm{F}(\mathrm{no} .[\%])$ & $23(79.3)$ & $194(55.3)$ & \\
\hline \multicolumn{3}{|l|}{ Surgery level } & \multirow{5}{*}{$\begin{array}{l}0.03, \dagger \\
0.019 \ddagger\end{array}$} \\
\hline Cervical & $7(20.0)$ & $149(41.2)$ & \\
\hline Thoracic & $1(2.8)$ & $9(2.5)$ & \\
\hline Lumbar & $27(77.1)$ & $204(56.4)$ & \\
\hline Cervical \& thoracic & $0(0.0)$ & $0(0)$ & \\
\hline \multicolumn{3}{|l|}{ Surgery (no. [\%]) } & \multirow{4}{*}{$\begin{array}{l}<0.001, \S \\
<0.001 \rrbracket\end{array}$} \\
\hline Anterior & $1(2.8)$ & $121(33.4)$ & \\
\hline Posterior & 34 (97.1) & $238(65.7)$ & \\
\hline Anteroposterior & $0(0)$ & $3(0.8)$ & \\
\hline Instrument use (no. [\%]) & $21(60)$ & $214(59.1)$ & 1 \\
\hline \multicolumn{3}{|l|}{ Age in yrs } & \multirow{4}{*}{$0.002^{* *}$} \\
\hline Mean (SD) & $64.4(12)$ & $57.4(13.4)$ & \\
\hline Median (IQR) & $66(16.5)$ & $59(19)$ & \\
\hline Range & $33-80$ & $19-87$ & \\
\hline $\begin{array}{l}\text { History of retention (no. } \\
{[\%] \text { ) }}\end{array}$ & $6(17.1)$ & $3(0.8)$ & $<0.001$ \\
\hline $\begin{array}{l}\text { History of BPH (M only) } \\
\text { (no. [\%])†† }\end{array}$ & $6(50)$ & $11(6.5)$ & $<0.001$ \\
\hline History of DM (no. [\%]) & $13(37.1)$ & $87(24)$ & 0.103 \\
\hline $\begin{array}{l}\text { Presenting w/ retention } \\
\quad(\text { no. }[\%])\end{array}$ & $3(8.6)$ & $1(0.3)$ & 0.002 \\
\hline $\begin{array}{l}\text { Presenting w/ constipa- } \\
\text { tion (no. [\%]) }\end{array}$ & $9(25.7)$ & $13(3.6)$ & $<0.001$ \\
\hline $\begin{array}{l}\text { Presenting w/ inconti- } \\
\text { nence (no. [\%]) }\end{array}$ & $3(8.6)$ & $10(2.8)$ & 0.199 \\
\hline Postop UTI (no. [\%]) & $5(14.3)$ & $17(4.7)$ & 0.035 \\
\hline $\begin{array}{l}\text { Intraop Foley placement } \\
\text { (no. [\%]) }\end{array}$ & $25(71.4)$ & $154(42.5)$ & 0.001 \\
\hline $\begin{array}{l}\text { Intraop complications } \\
\text { (no. [\%]) }\end{array}$ & $4(11.4)$ & $20(5.5)$ & 0.15 \\
\hline \multicolumn{3}{|l|}{ IVF administration in ml } & \multirow{4}{*}{$\begin{array}{l}0.071,{ }^{* *} \\
0.084 \ddagger \ddagger\end{array}$} \\
\hline Mean (SD) & $2429(1757)$ & $1867(1075)$ & \\
\hline Median (IQR) & $1839(1387)$ & 1600 (1291) & \\
\hline Range & $588-8742$ & $2.3-8200$ & \\
\hline \multicolumn{3}{|l|}{ Op time in mins } & \multirow{4}{*}{$\begin{array}{l}0.05,{ }^{* *} \\
0.013 \ddagger \ddagger\end{array}$} \\
\hline Mean (SD) & $212.5(129.8)$ & $166.8(103.3)$ & \\
\hline Median (IQR) & $169(125)$ & $140(112)$ & \\
\hline Range & $65-615$ & $28-730$ & \\
\hline PCA (no. [\%]) & $11(31.4)$ & $59(16.3)$ & 0.035 \\
\hline $\begin{array}{l}\text { Mean length of stay in } \\
\text { days (SD) }\end{array}$ & $6.3(2.7)$ & $4(2.4)$ & $<0.001$ \\
\hline
\end{tabular}

CONTINUED IN NEXT COLUMN 》
" CONTINUED FROM PREVIOUS COLUMN

$\mathrm{DM}=$ diabetes mellitus; $\mathrm{IQR}$ = interquartile range; $\mathrm{SD}=$ standard deviation.

* None of the males included in this category had BPH.

t Three groups: cervical, thoracic, lumbar.

‡ Two groups: cervical + thoracic versus lumbar.

$\S$ Three groups: anterior, posterior, and anteroposterior.

II Two groups: anterior versus posterior.

** t-test.

†† Women were excluded from this category.

㧊 Wilcoxon test.

non-retention group $(\mathrm{p}=0.035$, but $\mathrm{p}=0.078$ on multivariate analysis). Overall, $6 \%$ of the patients developed UTI. Foley catheters were intraoperatively placed in $71 \%$ of the patients who developed retention postoperatively and in $43 \%$ of those who did not have postoperative retention ( $\mathrm{p}=$ 0.001 , OR $=3.4$ ). Adverse events such as dural tear, postoperative CSF leak, bacteremia, abscess formation, and new neurological deficit occurred in 24 patients overall $(6 \%)$, in $11 \%$ of patients with retention, and in $6 \%$ of patients without retention $(p=0.15)$. Finally, $31 \%$ of patients who developed urinary retention were on a PCA during the postoperative period, whereas only $16 \%$ of those in the non-retention group were on a PCA in the immediate 24hour postoperative period $(\mathrm{p}=0.035, \mathrm{OR}=2.35$ ).

\section{Discussion}

Two previous studies in the literature remarked upon POUR in patients undergoing spine surgery. ${ }^{7,12}$ These studies looked only at lumbar laminectomies and found an incidence of POUR between $22.9 \%$ and $23.6 \%$. It is conceivable that our unique patient population or the greater variability in the operative procedures performed (via the inclusion of cervical and thoracic cases) was the reason for the lower incidence of POUR in our series; however, it could also be the result of our implementation of a bladder scanning and voiding protocol, as described above. More conservative management of patients at higher risk for retention with this protocol could lower this incidence still.

While the above-cited studies did not focus on identifiable risk factors for POUR in their populations, studies from other surgical specialties as well as our own have delineated certain identifiable risk factors that may place certain patients at higher risk for developing POUR.

\section{Patient Age and Sex}

The incidence of POUR increases with age, rising by a factor of 2.4 in patients more than 50 years old..$^{8,17,19-}$ ${ }_{21,27,28}$ In our study, age was noted to significantly influence retention, with older patients statistically more likely to experience POUR. In the literature, POUR has also been reported to occur more frequently in men $(4.7 \%)$ than in women $(2.9 \%)$ undergoing general surgery procedures, but in our initial analysis no difference was noted between sex and POUR for those undergoing elective spinal surgery. However, after controlling for comorbid $\mathrm{BPH}$, we demonstrated an increased POUR incidence in the female sex, which was not seen in prior results. Controlling for BPH is important to minimize variability in these analyses, and it is unclear if this was done in previous work. 
TABLE 2. Multivariate analysis for the development of POUR

\begin{tabular}{llc}
\hline \multicolumn{1}{c}{ Risk Factor } & \multicolumn{1}{c}{ OR $(95 \% \mathrm{Cl})$} & p Value \\
\hline Sex (F vs M) & $2.42(0.94,7.05)$ & 0.08 \\
\hline $\begin{array}{l}\text { Surgery level (cervical+thoracic } \\
\text { vs lumbar) }\end{array}$ & $2.7(1.14,7.1)$ & 0.032 \\
\hline BPH & $13.53(2.88,68.78)$ & 0.001 \\
\hline Chronic constipation & $4.35(1.46,12.64)$ & 0.007 \\
\hline UTI & $3.27(0.83,12.18)$ & 0.078 \\
\hline Intraop Foley placement & $3.42(1.52,8.17)$ & 0.004 \\
\hline PCA use & $2.4(1.10,5.10)$ & 0.001 \\
\hline
\end{tabular}

\section{Comorbidities}

Prior neurological dysfunction such as that resulting from stroke; spinal lesions; polio; multiple sclerosis; peripheral, alcoholic, or diabetic neuropathy; and BPH has been shown to predispose patients to develop urinary retention. ${ }^{2,27,29}$ In our study, a history of BPH, urinary retention, and constipation were all significant predictors of POUR. While the association with BPH is readily understood, we speculate that a history of chronic constipation and prior retention could reflect some underlying sphincter dysfunction. We additionally note that the significant association of POUR with preoperative constipation could be confounded by heavy narcotic use. Patients were not routinely scanned preoperatively to rule out preexisting retention (which would assist in diagnosis), although it would be difficult to perform in the immediate preoperative period. Future investigation via sacral electromyography or urodynamic studies in individuals with retention who later develop POUR may provide additional information.

\section{Intravenous Fluids and Duration of Surgery}

In patients undergoing hernia and anorectal surgery, IVF administration greater than $750 \mathrm{ml}$ during the perioperative period was found to increase the risk of POUR by a factor of 2.3, but there have been conflicting findings in studies looking at postoperative retention as a function of operative time. ${ }^{1,8,13,16,18,21,27,29,32}$ Our study showed a significant correlation between operative time and the incidence of POUR, but not the volume of intraoperative IVFs and the incidence of POUR, although a trend toward significance was noted. The wide range of IVF data may have limited our analysis, but controlling for this as well as the amount of anesthetic administered could not be performed retrospectively, possibly confounding these results. Additionally, the degree of difficulty in longer procedures, as well as the manipulation of neural elements during these cases, could contribute to POUR independent of operative time. Placement of a Foley catheter also increased the likelihood of POUR in our series, but this finding probably reflects the fact that a catheter was placed before surgeries that were expected to be lengthy.

\section{Systemic Narcotic Use and Ambulation}

Systemic opioids have been shown to inhibit acetylcholine release from the sacral parasympathetics, which control detrusor emptying. ${ }^{2}$ In cholecystectomy and appendectomy patients, POUR was related to the amount of narcotics used postoperatively, with greater POUR rates in those who used a PCA as opposed to intermittent intramuscular delivery. In our study, those on a PCA postoperatively were more than twice as likely to develop POUR than those who were not. This reliance on a PCA for pain control may have also contributed to the longer time to ambulation for individual patients, yet a standardized time could not be determined for our study as each patient and surgery interacted differently with perioperative factors to determine when first ambulation would occur. Additionally, the longer the catheters remained in place, the more limited patients were in their ability to ambulate, in a cycle that could prolong their time to discharge. Practitioners should opt for earlier discontinuation of catheters in low-risk patients to promote early ambulation. When multivariate analyses were performed for operative time and PCA administration, PCA remained a significant independent predictor of POUR. Future studies could look at narcotic use in greater detail and determine the dosing and administration parameters most likely to contribute to the occurrence of POUR.

\section{Surgical Site and Instrumentation}

Those undergoing lumbar surgery were the most likely group to experience POUR. Many of the most extensive surgical procedures in terms of duration and intraoperative blood loss were lumbar fusion procedures in our series, and the effect of increased operative time, IVF administration, and the use of PCA may also be factors in these patients experiencing POUR. A theoretical neurological explanation for POUR may be the temporary effects of any manipulation around the dural sac causing nerve stretch or inflammation, but this is probably unlikely as functional disturbance of the sacral roots may also be expected to be associated with radicular pain or lower-extremity motor dysfunction, findings not observed in our patients. No statistically significant incidence of POUR was noted between patients who did and did not undergo instrumentation, regardless of surgical level. Of note, the number of patients with POUR in the cervical and thoracic groups was small, making it difficult to make generalities about POUR in these individual groups.

\section{Surgical Complications}

Three patients developed POUR as part of a cauda equina syndrome in conjunction with an epidural hematoma. In all of these cases, there were additional symptoms of saddle anesthesia and increased leg pain with foot weakness, features that were not noted in patients with typical POUR. Other operative complications such as dural breach resulting in postoperative spinal fluid leakage, abscess formation, and the development of new neurological deficits were not statistically associated with the incidence of POUR.

\section{Hospital Length of Stay}

The incidence of POUR was significantly associated with a longer hospital stay, but it is unclear if POUR is 
the sole reason for this finding. Foley catheter placement, the complexity and duration of surgery, and comorbidities may also play a role in prolonging the hospital stay. Identifying at-risk patients and managing them sooner toward a successful trial of voiding would probably allow for their earlier discharge from the hospital.

While temporary catheterization at the end of long cases has been suggested, it is unclear if this would be sufficient to prevent POUR in certain low-risk patients, and it may even increase dependence on the catheter to void in these patients when it could have otherwise been avoided. Additionally, the absence of a short-term catheter in high-risk patients would almost certainly increase the incidence of immediate POUR and likely result in eventual catheterization. Further research on acute or intermittent as compared with the prolonged management of POUR over days is warranted and can improve outcomes.

Potential limitations of our study include the extent to which a single institution's data can be generalizable to other centers, as well as the variability of surgical management and postoperative care among the 5 contributing surgeons in our series. A multicenter analysis in the future is required for greater generalizability. Albeit prevalent, POUR occurs in a small number of patients, making it difficult to determine the true significance of identified risk factors despite the large number of patients screened. The variability of Foley catheter tolerance and discontinuation varied from patient to patient, as did the time to ambulation and intraoperative anesthetic use, which may have influenced any subsequent occurrence of POUR. Operative time and Foley catheter placement were also intertwined as the longer, more complex cases were the ones during which a Foley catheter was placed, possibly further confounding this variable. The variability in preoperative neurological conditions may have influenced our data, but controlling for this would reduce the generalizability of our data and limit the number of patients studied, as it would be difficult to include patients with only a specific type of pathology. Finally, the retrospective nature of our study limits the generalizability of our results.

\section{Conclusions}

Risk factors for the development of POUR include a history of urinary retention, chronic constipation, lengthy posterior lumbar surgery, longer operative times, a history of BPH, and PCA usage. Awareness of the risk factors for the development of POUR may be useful for identifying patients who should have prophylactic Foley catheter placement preoperatively and for those who need particular vigilance when they are due to void postprocedure or on postdiscontinuation of the catheter. This greater awareness may also improve lengths of hospital stays for patients undergoing elective spinal surgery without the above risk factors, who may tolerate voiding spontaneously after a surgical procedure. While the cause of POUR is not fully clear and may be the consequence of the effects of surgical stress, anesthesia, or perioperative medications, it is rarely caused by the feared complication of postoperative cauda equina syndrome from epidural hematoma, in which there is associated saddle anesthesia, leg pain, and leg weakness. However, it is imperative to delineate these 2 causes so that each can be treated accordingly and so that neurological function can be preserved.

\section{Acknowledgments}

We acknowledge Janet McHenry, DNP; Barbara Lyall, ANP $\mathrm{BC}$; and Orlene Hoskinson, FNP BC, for their care of the patients in this study. We also thank Dr. Adam Sandler for his contributions.

\section{References}

1. Bailey HR, Ferguson JA: Prevention of urinary retention by fluid restriction following anorectal operations. Dis Colon Rectum 19:250-252, 1976

2. Baldini G, Bagry H, Aprikian A, Carli F: Postoperative urinary retention: anesthetic and perioperative considerations. Anesthesiology 110:1139-1157, 2009

3. Brown AR, Weiss R, Greenberg C, Flatow EL, Bigliani LU: Interscalene block for shoulder arthroscopy: comparison with general anesthesia. Arthroscopy 9:295-300, 1993

4. Dobbs SP, Jackson SR, Wilson AM, Maplethorpe RP, Hammond RH: A prospective, randomized trial comparing continuous bladder drainage with catheterization at abdominal hysterectomy. Br J Urol 80:554-556, 1997

5. Gönüllü NN, Gönüllü M, Utkan NZ, Dülger M, Gökgöz S, Karsli B: Postoperative retention of urine in general surgical patients. Eur J Surg 159:145-147, 1993

6. Iorio R, Healy WL, Patch DA, Appleby D: The role of bladder catheterization in total knee arthroplasty. Clin Orthop Relat Res (380):80-84, 2000

7. Jellish WS, Thalji Z, Stevenson K, Shea J: A prospective randomized study comparing short- and intermediate-term perioperative outcome variables after spinal or general anesthesia for lumbar disk and laminectomy surgery. Anesth Analg 83:559-564, 1996

8. Keita H, Diouf E, Tubach F, Brouwer T, Dahmani S, Mantz J, et al: Predictive factors of early postoperative urinary retention in the postanesthesia care unit. Anesth Analg 101:592 596,2005

9. Lamonerie L, Marret E, Deleuze A, Lembert N, Dupont M, Bonnet F: Prevalence of postoperative bladder distension and urinary retention detected by ultrasound measurement. Br J Anaesth 92:544-546, 2004

10. Li S, Coloma M, White PF, Watcha MF, Chiu JW, Li H, et al: Comparison of the costs and recovery profiles of three anesthetic techniques for ambulatory anorectal surgery. Anesthesiology 93:1225-1230, 2000

11. Lingaraj K, Ruben M, Chan YH, Das SD: Identification of risk factors for urinary retention following total knee arthroplasty: a Singapore hospital experience. Singapore Med J 48:213-216, 2007

12. McLain RF, Kalfas I, Bell GR, Tetzlaff JE, Yoon HJ, Rana $\mathrm{M}$ : Comparison of spinal and general anesthesia in lumbar laminectomy surgery: a case-controlled analysis of 400 patients. J Neurosurg Spine 2:17-22, 2005

13. Mulroy MF, Larkin KL, Hodgson PS, Helman JD, Pollock JE, Liu SS: A comparison of spinal, epidural, and general anesthesia for outpatient knee arthroscopy. Anesth Analg 91:860-864, 2000

14. Pavlin DJ, Rapp SE, Polissar NL, Malmgren JA, Koerschgen M, Keyes H: Factors affecting discharge time in adult outpatients. Anesth Analg 87:816-826, 1998

15. Peiper C, Töns C, Schippers E, Busch F, Schumpelick V: Local versus general anesthesia for Shouldice repair of the inguinal hernia. World J Surg 18:912-916, 1994

16. Petersen MS, Collins DN, Selakovich WG, Finkbeiner AE: Postoperative urinary retention associated with total hip and 
total knee arthroplasties. Clin Orthop Relat Res (269):102108, 1991

17. Petros JG, Alameddine F, Testa E, Rimm EB, Robillard RJ: Patient-controlled analgesia and postoperative urinary retention after hysterectomy for benign disease. J Am Coll Surg 179:663-667, 1994

18. Petros JG, Bradley TM: Factors influencing postoperative urinary retention in patients undergoing surgery for benign anorectal disease. Am J Surg 159:374-376, 1990

19. Petros JG, Mallen JK, Howe K, Rimm EB, Robillard RJ: Patient-controlled analgesia and postoperative urinary retention after open appendectomy. Surg Gynecol Obstet 177:172-175, 1993

20. Petros JG, Rimm EB, Robillard RJ: Factors influencing urinary tract retention after elective open cholecystectomy. Surg Gynecol Obstet 174:497-500, 1992

21. Petros JG, Rimm EB, Robillard RJ, Argy O: Factors influencing postoperative urinary retention in patients undergoing elective inguinal herniorrhaphy. Am J Surg 161:431-434, 1991

22. Salvati EP, Kleckner MS: Urinary retention in anorectal and colonic surgery. Am J Surg 94:114-117, 1957

23. Sanjay P, Woodward A: Inguinal hernia repair: local or general anaesthesia? Ann R Coll Surg Engl 89:497-503, 2007

24. Song D, Greilich NB, White PF, Watcha MF, Tongier WK: Recovery profiles and costs of anesthesia for outpatient unilateral inguinal herniorrhaphy. Anesth Analg 91:876-881, 2000

25. Spector LR, Madigan L, Rhyne A, Darden B II, Kim D: Cauda equina syndrome. J Am Acad Orthop Surg 16:471-479, 2008

26. Stallard S, Prescott S: Postoperative urinary retention in general surgical patients. Br J Surg 75:1141-1143, 1988

27. Tammela T, Kontturi M, Lukkarinen O: Postoperative urinary retention. I. Incidence and predisposing factors. Scand J Urol Nephrol 20:197-201, 1986

28. Tammela T, Kontturi M, Lukkarinen O: Postoperative urinary retention. II. Micturition problems after the first catheterization. Scand J Urol Nephrol 20:257-260, 1986

29. Toyonaga T, Matsushima M, Sogawa N, Jiang SF, Matsumura $\mathrm{N}$, Shimojima Y, et al: Postoperative urinary retention after surgery for benign anorectal disease: potential risk factors and strategy for prevention. Int J Colorectal Dis 21:676682, 2006

30. Walts LF, Kaufman RD, Moreland JR, Weiskopf M: Total hip arthroplasty. An investigation of factors related to postoperative urinary retention. Clin Orthop Relat Res (194):280282, 1985

31. Young DV: Comparison of local, spinal, and general anesthesia for inguinal herniorrhaphy. Am J Surg 153:560-563, 1987

32. Zaheer S, Reilly WT, Pemberton JH, Ilstrup D: Urinary retention after operations for benign anorectal diseases. Dis Colon Rectum 41:696-704, 1998

\section{Disclosures}

The authors report no conflict of interest concerning the materials or methods used in this study or the findings specified in this paper.

\section{Author Contributions}

Conception and design: Altschul, Jada, Nasser, Yassari, Houten. Acquisition of data: Kobets, Altschul, Nakhla, Jada, Nasser, Houten. Analysis and interpretation of data: Kobets, Altschul, Nakhla, Jada, Nasser, Houten. Drafting the article: Kobets, Altschul, Nakhla, Jada. Critically revising the article: Kobets, Altschul, Kinon, Yassari, Houten. Reviewed submitted version of manuscript: Kobets, Altschul, Nakhla, Kinon, Yassari, Houten. Approved the final version of the manuscript on behalf of all authors: Kobets. Statistical analysis: Kobets, Altschul, Kinon. Study supervision: Kobets, Altschul, Yassari, Houten.

\section{Supplemental Information Previous Presentations}

Portions of this work were presented in poster form at the Annual Meeting of the American Association of Neurological Surgeons held in Washington, DC, on May 2-6, 2015.

\section{Correspondence}

Andrew J. Kobets, Department of Neurosurgery, Montefiore Medical Center, 3316 Rochambeau Ave., 1st Fl., Bronx, NY 10471.email: ajkobets@yahoo.com. 